\title{
RAPID ROADWAY DEVELOPMENT
}

\author{
Luke Meers ${ }^{1}$, Stephen van Duin ${ }^{1}$, Matt Ryan ${ }^{2}$ \\ ${ }^{1}$ University of Wollongong \\ Northfields Avenue, \\ Gwynneville, New South Wales, \\ Australia \\ (lmeers@uow.edu.au) \\ ${ }^{2}$ Mining Attachments \\ 6 Kiama Ave, \\ Bangalee, Queensland, \\ Australia \\ (matt@miningattachments.com.au)
}




\title{
RAPID ROADWAY DEVELOPMENT
}

\begin{abstract}
Roadway development rates in Australian underground coal mines are failing to keep pace with modern longwall systems and are unlikely to sustain further improvements in longwall productivity into the future unless step change improvements to roadway development equipment and practices are made. Bottlenecks which limit and constrain improved production and impact the safety of operators have been identified through a series of industry surveys, with the manual installation of strata support materials, consumables delivery, coal haulage and monorail installation being highlighted as major areas to improve development performance. This paper looks at research being carried out at the University of Wollongong in designing an integrated system approach for the fully automated handling and installing of development consumables, and the systems required to support these activities. A series of hard automation manipulation devices have been demonstrated in surface trials and the results indicate that rapid roadway development can be achieved.
\end{abstract}

\section{KEYWORDS}

Automation, robotics, manipulation, roadway development, roof support, monorail, consumables, mining

\section{INTRODUCTION}

Roadway development in underground coal mining has been identified as restricting mine production rates. Improved longwall technologies have allowed coal extraction rates to double every 10 years since 1970, whilst over the same period, roadway development advance rates have remained largely the same (Gibson, 2010). Step changes to roadway development processes are required if rapid advance rates are to be achieved, however, roadway development is a unique and complicated process requiring specific equipment that can operate in harsh underground conditions and in limited space.

Continuous Miners (CM) in Australian longwall mines use essentially a non-continuous process, as they cut (coal removal from face) and then stop while strata support materials, usually steel mesh and bolts are secured before further cutting can continue. The methods currently employed to deliver, handle and install the consumable materials require high levels of human intervention and cannot be improved to the rates needed to support longwall production. Additionally, the manual handling support activities are carried out in a confined space in close proximity of rotating components, contributing to the high rates of injuries reported by personnel working on CMs (Burgess-Limerick, 2011). Australian mine design guidelines ("Guideline for bolting", 2010) have been introduced in an attempt to reduce the risks associated with operating 
this equipment, however the rates required for rapid roadway development are likely to undermine this progress and dramatically increase the load, fatigue and injury rates of personnel. Alternatively, automation coupled with integrated design of all roadway equipment could see significant improvements in advance rates and reduction of injuries.

The integration of the multiple processes in roadway development is critical to improving advance rates but is likely to involve significant changes to the current technology. In Australian longwall mines shuttle cars are mostly used to transport coal from the CM to the belt conveyor. Increased advance rates coupled with the periods when the CM is positioned further away from the fixed conveyor, mean shuttle car travel times constrain the process. Current practice also involves the manual installation of ventilation duct sections and extension of services to the CM. Some mines utilise manually installed monorail to reduce the handling of these items. All these activities become increasingly difficult if not impossible at the advance rates required to match longwall production. The highly specific CM design, coupled with the slow design evolution of roadway development equipment, means that little if any of the process is automated. However, it is automation and the system integration of these processes that may hold the key to improving roadway development rates to the levels required.

An Australian industry study comprising of mining companies, Original Equipment Manufacturers (OEMs), contractors and suppliers, identified key elements to improve roadway development rates as well as operator safety (Gibson, 2005, 2008). The key findings were:

- $\quad$ Roof and rib support were found to be the most critical constraint limiting production rates;

- $\quad$ Coal haulage, particularly the stop-start nature of shuttle cars, require change to support higher advance rates;

- Installation of ventilation ducting and support service require mechanisation;

- $\quad$ Integrated system required for the delivery, supply and handling of strata support consumables including mesh, bolts and washers.

In light of this study, the University of Wollongong (UOW) is conducting research in several critical areas. Firstly, mechanised automated equipment for the handling and installation of consumable items on the continuous miner has been developed and successful full scale prototypes tested. Secondly, a conceptual analysis has been used to evaluate the interaction between the CM, coal haulage and consumables delivery systems. A concept design which allows for automation of these functions has been created. And thirdly, a further project has developed a design for mechanised, self-installing monorail sections to eliminate the manual installation of rails, ducting and services in the roadway (Meers \& van Duin, 2012).

In addition to research undertaken by UOW, several other technologies are considered critical to achieving rapid roadway development. Self drilling bolts (SDB) have been trialled and implemented at numerous mines (Gibson, 2007, Gray, 2007, Bayerl et al., 2009). These bolts play a critical part in moving towards automated roadway development by reducing the total number of steps and handling processes involved in the drilling sequence. Semi-automated bolting rigs are in various stages of development by several manufacturers and if combined with the technology discussed in this paper, could see full automation achieved. 
To achieve a truly automated roadway development process requires the removal of operators from the face area and from the CM itself. This necessitates the miner and other roadway equipment to be either remotely operated, or ideally, self-steering and fully programmable. Position feedback of the longwall shearer ranging arm and roof support systems already utilise real time control. Some commercially available systems offer inertial navigation and research is continuing to drive this area of the industry forward (Corke et al. 2008; Kelly et al. 2003; Fan et al. 2010). However, until recently, the self navigation of mobile equipment in the roadway development process has been limited. Research undertaken by the Commonwealth Scientific Industry Research Organisation in Australia has involved automation of the CM cutting cycle as well as developing the technology required to self-steer CMs and other roadway vehicles (Reid et al., 2011).

It has become increasingly apparent that for high production automated roadway development to be possible, a holistic design approach is necessary. The confined space within the roadway, the continual advance of all the equipment along the tunnel, combined with the conflicting direction of flow of consumables and coal extraction means that no part of the roadway system can be considered in isolation. The continuous miner, services, coal haulage and consumable delivery systems all support and impact on each other. As such, automation of these systems must be considered and developed as an integrated system. This paper presents the work undertaken by the University of Wollongong in endeavouring to use this holistic design approach. Automation solutions and concepts are presented for a range of roadway equipment. In the following sections, each of these systems are described and key outcomes presented as a solution for high capacity automated roadway development.

\section{CONTINUOUS MINER CONSUMABLES HANDLING SYSTEM}

For every one metre advance in a typical roadway development cycle (using a 6 roof bolt, 4 rib bolt per metre bolting density), 23 consumable items need to be handled consisting of 10 bolts, 10 washer/plates, 1 steel roof mesh module $(5.2 \times 1.1 \mathrm{~m})$, and 2 steel rib mesh sheets $(1.2 \times 1.6 \mathrm{~m})$. This number increases when installing cuttable consumables which are also considered in the design. To manipulate these items, a total of six subsystems have been developed, which include:

1. Bolt delivery system

2. Washer delivery system

3. Roof bolt manipulator
4. Rib bolt manipulator

5. Roof mesh manipulator

6. Rib mesh manipulator

The automation system for the continuous miner was designed to suit mine roadway dimensions with a minimum roof height of $2.8 \mathrm{~m}$ and minimum width of $5 \mathrm{~m}$; a strata support bolt density of 6 roof bolts and 4 rib bolts per metre advance. The system also relies on using either one of two types of SDB. A key challenge to be addressed by the research was creating a system which could be retrofitted to an existing CM in order to prove the capability of the automation equipment without requiring a specifically designed CM. Whilst this approach makes the research more economically feasible, the space constraints in adapting to existing equipment significantly increase the complexity and difficulty of the design work.

The roof mesh manipulation system developed is located centrally and along the top of the CM. Roof mesh sheets, positioned longitudinally along the CM are conveyed from the rear 
of the machine to the front via a chain conveyor; the sheet is lifted and rotated via a turntable, before being transferred into position above the drill rigs.

All other parts of the automation system are duplicated on both sides of the machine. The bolt magazines hold a small capacity of both roof and rib bolts which can be dispensed on demand. The magazine conveys a bolt down a race delivering the roof or rib bolt to the respective bolt manipulator. The bolt manipulators use driven roller grips to both secure and convey the bolts. The manipulators operate on multiple axes to rotate and drive the bolts into the bolting rigs before they are clamped at the head plate.

Simultaneous to bolt transfer, washer plates are conveyed from the rear of the machine to the rib bolter, where they are dispensed down a chute and into a locating pocket. This pocket is then transferred along a track positioning the washer within the bolt conveying centreline where it is picked up by the bolt.

A single sheet of rib mesh is transferred from a small capacity magazine either side of the platform. Each piece of mesh can be automatically dispensed on demand. The storage unit separates a single piece of mesh onto a transfer arm where a chain conveyor transfers the mesh along the side of the continuous miner and positions it against the rib-spall protection shield. Gripping cylinders secure the mesh before the shield extends towards the coal rib. An image of the full system is shown in Figure 1.

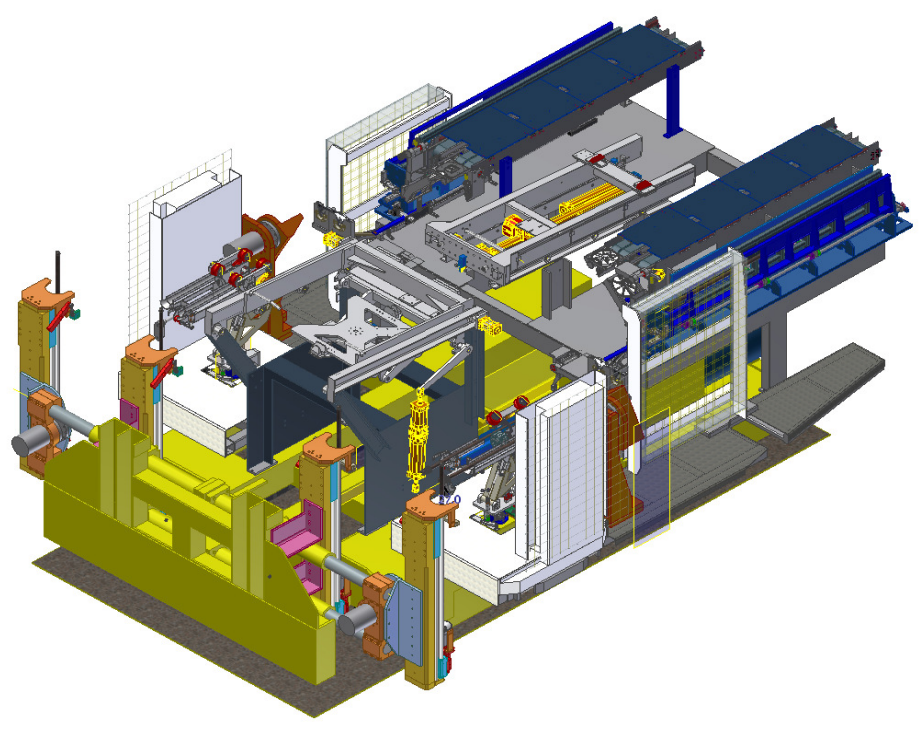

Figure 1 - Automation equipment on a mobile multi-bolter unit

\section{System Integration and Demonstrations}

Full modelling and simulation of the integrated system was performed using several software packages. The computer simulation allows assessment of full system dynamics including potential clashes, realistic cycle times, detailed sequencing and design revisions. This analysis proves highly valuable in refining designs and sequences before any fabrication work is 
carried out. The figure below show a screen shot during some simulation work using Dassault Systémes ${ }^{\circledR}$ Delmia software.

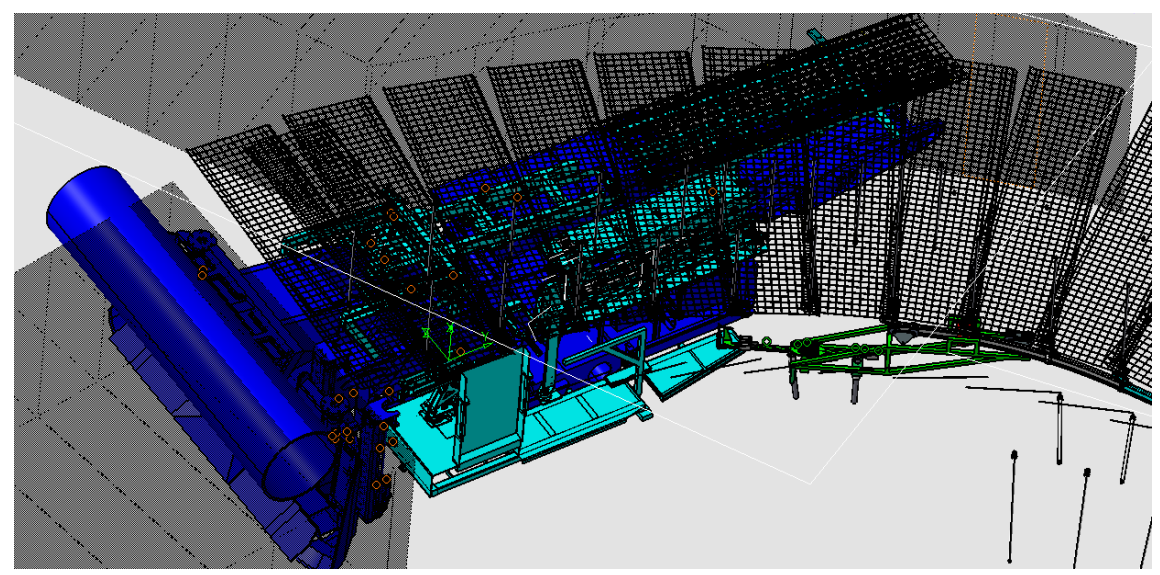

Figure 2 - Simulation of the CM installing mesh and bolts

Figure 3 shows the complete CM materials handling system on a laboratory test frame on which the automation system was mounted and tested. The dimensions of the frame represent the major mounting points of a continuous miner frame and allowed for the convenient experimentation in a laboratory setting.

The demonstration has proven that a solution for automated bolting and meshing is achievable. Some major findings from the prototype work include:

- Automation of bolt and meshing activities is possible on a continuous miner without having to change the fundamental design of the miner platform and its operation.

- The cycle times achieved by the integrated automation are consistent with increased roadway development rates of at least 10 metres per operating hour.

- An appreciation of the scale of mechanisms, actuation and control required to automate the process.

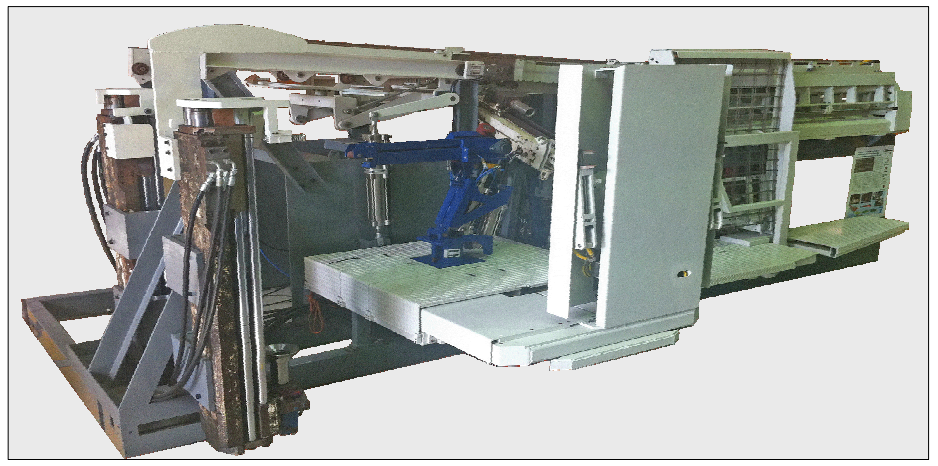

Figure 3 - Laboratory demonstration and testing unit 
Following the successful demonstration of the unit in Figure 3, work has continued to further optimise the automation. Design revisions have been made to each system to improve robustness and the interaction between modules as well as replicating the right hand side of the miner. The complete system is being prepared for a full surface demonstration in a 10 metre length roadway. This will demonstrate that the automation equipment can successfully operate for successive cycles in an operational environment.

\section{SELF-EXTENDING MONORAIL SYSTEM}

Monorail systems are utilised during roadway development in some Australian mines to carry the ventilation ducting, and services such as air, water and cabling to the CM. These monorail systems virtually eliminate the handling of the cumbersome ventilation ducting and services but replace this with the need to install the heavy (approximately $15-40 \mathrm{~kg}$ ) monorail sections. These beams are typically installed from the rear of a CM.

A concept for a self-extending automated monorail has been developed (Figure 4). This design utilises a mechanism which travels along the installed rail sections. The manipulator drives outbye of the CM to collect the next successive rail from a delivery device and tracks to the inbye end and lifts the rail into the connection position. It then drives back and tilts the rail up to complete the connection to the last section. A second part of the mechanism lifts a four bar linkage on the rail itself to connect to a roof bolt previously installed from the CM. The self extending monorail system has been fully designed and a prototype built for further testing.

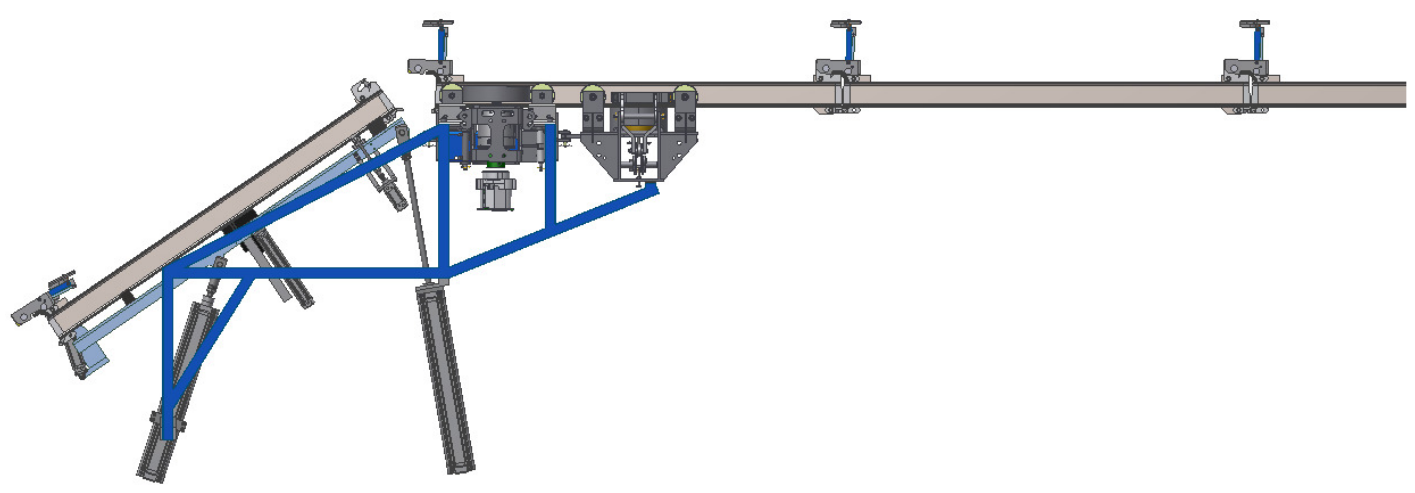

Figure 4 - Monorail manipulator with monorail section

Successfully implemented, monorail technology would provide integral support to the automation on the miner as well as eliminate the common injuries associated with manual installation of ventilation ducting or monorails sections (Smith \& Hagen 2012). It may also be utilised for supporting automated continuous coal haulage equipment or for transport of consumables to the miner.

\section{CONSUMABLES DELIVERY SYSTEM}

The automation technology described above has the potential to markedly improve the installation rate of roof support materials. An effect of which is an increase in the required 
delivery rate of consumables beyond what is practical for manual handling. For mines achieving rapid roadway development rates in excess of 7 metres per operating hour (MPOH) and approaching a target rate of $10 \mathrm{MPOH}$, material delivery becomes a significant challenge. It is calculated that for $10 \mathrm{MPOH}$ advance, 1.4 to 1.6 tonne of consumables is required per hour. This equates to 40 tonnes of material required to complete a 100 metre pillar cycle.

It is anticipated that the increased volume of materials to be handled requires new methods for loading the continuous miner. It becomes clear from a process point of view that the numbers of bolts and mesh required to service the rapid roadway development process would deplete the physical capacity of existing on-board storage methods at too greater rate for them to remain practical. Research work was undertaken by Mining Attachments Pty Ltd in partnership with University of Wollongong to evaluate the potential delivery options and deliver a concept which satisfies the required delivery rates and fits on or around a coal haulage system.

The research included a thorough analysis of the logistics of shuttle car versus continuous haulage systems particularly in light of the space required in the roadway to fit both the haulage and consumable delivery systems. 3D simulation and modelling work coupled with industry feedback delivered a concept for a tracked consumables delivery device which transports one metre advance worth of materials at a time. Shown in Figure 5, this device travels on top of a modular flexible rail system and is reloaded at a docking station located in a cut through.

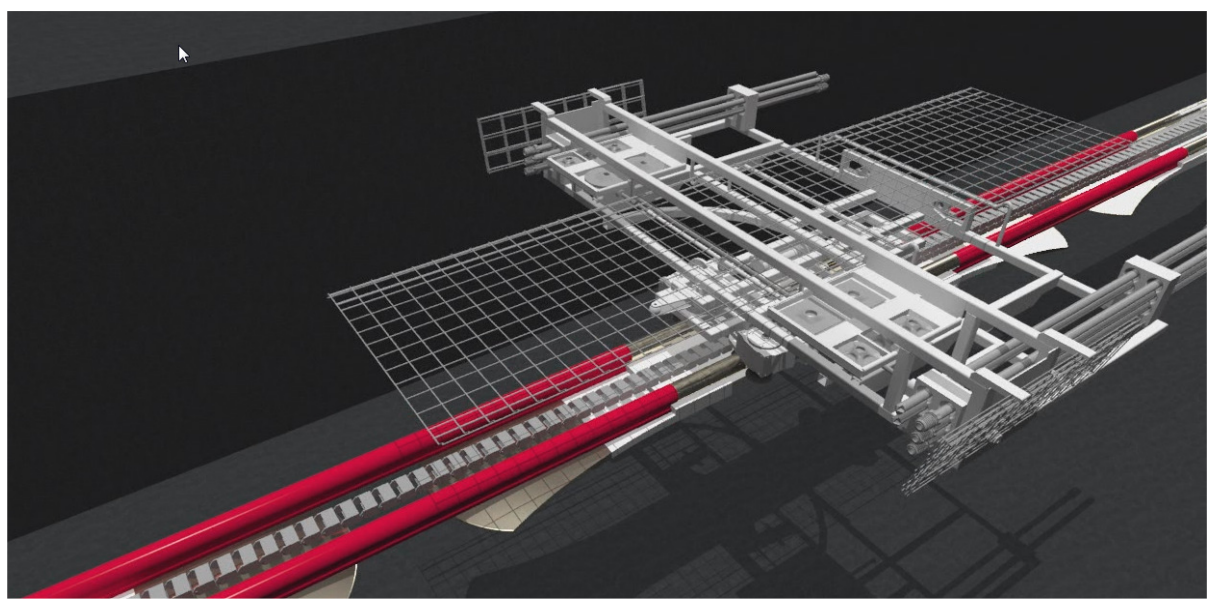

Figure 5 - Tracked consumables delivery system

This system provides a compact solution to deliver the required materials to the CM, whilst occupying minimal cross sectional space in the roadway, thus allowing co-occupation with a continuous haulage system. Key findings of this research included:

- It was evaluated that at advance rates approaching $10 \mathrm{MPOH}$, shuttle cars become impractical.

- Minimising the cross sectional area consumed by all equipment in the roadway was found to be critical to allow access for services, coal haulage and consumables movement concurrently.

- Storage of consumables on or behind the miner becomes impractical when the 
volumes required for 10MPOH are considered.

- $\quad$ Simple delivery equipment with minimal moving parts increases the likelihood of a successful automated solution for consumables handling.

\section{CONCLUSIONS}

Design for the automation of roadway development tasks is non-trivial and several constraints specific to the industry need to be considered. By using a laboratory above ground demonstration a satisfactory solution for automatic control and manipulation of roof and rib support materials now exists and shows that the prototype machinery and control can potentially remove the operator from the dangerous face conditions in an underground production environment.

The work completed on the CM, materials delivery, and monorail installation systems has identified and quantified the time savings that can be achieved through automated repeatability. When taken to full fruition, cycle times, and therefore overall development rates, are expected to be improved towards a target of 10 metres per operating hour.

The prototype design, simulation work and laboratory testing have significantly reduced the technical risk in proceeding forward and the further demonstrations performed on the multibolter unit and the monorail sections are expected to bring the technology and risks management to a stage ready for full OEM development.

The work undertaken by the University of Wollongong and Mining Attachments highlights the need for an integrated systems approach to automation in underground roadway development. The research and development discussed in this paper has identified and produced solutions for the major roadway development tasks. These automated technologies rely heavily on interface compatibility, position awareness and communication with each other, and as such, automated rapid roadway development is most likely to be achieved by considering all systems as an integrated solution.

\section{ACKNOWLEDGEMENTS}

The researchers of this project would like to thank the Australian Coal Association Research Program and the Roadway Development Task Group for their on-going support with funding and review. The researchers would also like to acknowledge the many individuals from industry who have participated in providing valuable feedback and research direction at various stages during the course of the research. 


\section{REFERENCES}

Bayerl, M., Danzebrink, B., Thyrock, K., Opolony, K., \& Gollnick, I. (2009). Application of Hilti One Step Bolts for roadway support in German deep coal mines, Proceedings 28th International Conference on Ground Control in Mining, ICGCM, p 59-69. Phoenix, AZ

Burgess-Limerick, R. (2011). Injuries associated with underground coal mining equipment. The Ergonomics Open Journal, 4, (Suppl. 2-M1), 62-73

Corke P, Roberts J, Cunningham J \& Hainsworth D. (2008). Mining robotics. In: Springer Handbook of Robotics, Bruno Siciliano and Oussama Khatib (Eds), Springer-Verlag, Berlin Heidelberg, pp 1127-1150. ISBN: 978-3-540-23957-4.

Gibson, G. (2005). Australian Roadway Development - Current status (Australian Coal Association Research Program report C15005), Australia.

Gibson, G. (2008). Improving roadway development in underground coal mines, In the proceedings for the AusIMM $13^{\text {th }}$ Australian Tunnelling Conference, V1.3, 978-1920806-80-4.

Gibson, G. (2010). CM2010 Roadway development research and development strategy, Mine Site Automation and Communication Conference, Perth, Australia.

Gray, P. (2007). Self drilling rock bolt technology - development of self drilling rock bolt (Australian Coal Association Research Program report C11028). Australia.

Industry and Investment NSW, Mine Safety Standards, (2010), Guideline for bolting and drilling plant in mines (Safety Standards, MDG 35 090831). New South Wales, Australia.

Kelly, M., Hainsworth, D., Reid, D., Lever, P., \& Gurgenci, H. (2003) Longwall Automation A new approach, Third International Symposium "High Performance Mine Production”, Aachen, June 11-12.

Meers, L., \& van Duin, S., (2012). Design for Automated Self Advancing Monorail, 12th Coal Operators' Conference, University of Wollongong \& the Australasian Institute of Mining and Metallurgy, 109-113. Australia.

Reid, D. C., Ralston, J. C., Dunn M. T., \& Hargrave, C. O. (2011). A major step forward in continuous miner automation, Proceedings of the 11th Underground Coal Operators' Conference. University of Wollongong \& the Australasian Institute of Mining and Metallurgy, 165-171.

Smith, B., \& Hagan, P. (2012). Improvements in Gate Road Development Rates Using a Monorail System. Research Projects Review 2011, 51.

Fan, Q., Li, W., Wang, Y., Zhou, L., Yang, X., \& Ye, G. (2010). Control strategy for an intelligent shearer height adjusting system, Mining Science and Technology (China), Volume 20, Issue 6, Pages 908-912. 